\title{
Evaluation of agreement between clinical and histopathological diagnosis of subtype of leprosy by skin punch biopsy
}

\author{
Suman Poudel (iD, Sunita Ranabhat, Gita Pun \\ Department of Pathology, Gandaki Medical College Teaching Hospital, Pokhara
}

\begin{abstract}
Introduction: Leprosy is chronic granulomatous disease caused by Mycobacterium leprae. Clinically diagnosed cases of leprosy can be evaluated by punch biopsy. It can be classified according to Ridley and Jopling Classification. Objective: To study the different spectrum of leprosy and its Bacillary Index (BI), evaluate the agreement between clinical and histopathological diagnosis. Materials and Methods: This is a hospital based cross sectional retrospective study done for the period of 6 months from January to June 2019. The data were subjected to kappa analysis by using SPSS version 24 to see the agreement between clinical and histopathological diagnosis. Results: Out of 62 cases of clinically diagnosed cases of leprosy three (4.83\%) cases turned out to be other granulomatous diseases. According to Ridley and Jopling classification, clinical and histopathological agreement was seen in 38 (61.29\%) cases. Agreement of 100\% was seen in Indeterminate leprosy (IL) and Borderline tuberculoid leprosy (BT). The BI was more in Lepromatous leprosy (LL), Borderline lepromatous (BL) whereas IL, BT and Tuberculoid leprosy (TT) showed less BI. Overall there was moderate agreement between clinical and histopathological diagnosis (kappa- 0.505) which was statistically significant ( $\mathrm{p}$ value $<0.05$ ). Conclusion: There was moderate agreement between the clinical and histopathological diagnosis of subtype of leprosy. The Bacillary load was high in LL whereas least in TT and is determined by immune system.
\end{abstract}

Key words: Bacillary index, Leprosy, Ridley and Jopling Classification

\section{*Correspondence to:}

Dr. Suman Poudel, MD

Lecturer, Department of Pathology, GMC-TH, Pokhara

Email: batigsu@gmail.com

Submitted: $6^{\text {th }}$ April 2020

Accepted: $3^{\text {rd }}$ June 2020

To Cite : Poudel S, Sunita R, Pun G . Evaluation of agreement between clinical and histopathological diagnosis of subtype of leprosy by skin punch biopsy JGMC Nepal. 2020;13(1):4-8. DOI: 10.3126/igmcn. v13i1.28357

\section{INTRODUCTION}

Leprosy has become a major health problem in Nepal. It has been endemic in tropical countries, mainly in underdeveloped or developing countries like Nepal. ${ }^{1}$ Hansen's disease is a chronic granulomatous disease caused by M. leprae, an acid fast bacillus. The clinical, pathological and immunological criteria of the Ridley and Jopling classification provide the basis for the classification of the various forms of the disease, including indeterminate (IL), tuberculoid (TT), borderline tuberculoid (BT), mid-borderline (BB), borderline lepromatous (BL), and lepromatous (LL) form. The spectrum of disease as such depends upon the immune status of the patient. ${ }^{2}$ The cellular response is seen in TT whereas humoral response is seen in LL. ${ }^{3}$

The complications and nerve damage can be prevented by early diagnosis of the disease. ${ }^{4}$ Though clinical examination is essential, many skin lesions may share the common clinical findings. In difficult cases, for good management 
of patients, histopathological studies are essential. ${ }^{5}$ However, it requires good correlation between clinical variables like site, duration, number, nature of lesions and histopathological features to come to final diagnosis. Also histopathological examination is required to separate different types of granulomatous skin lesions like lupus vulgaris, Hansen's disease, sarcoidosis and fungal infection. ${ }^{6}$

In this present study, we study subtypes of leprosy, their BI and assess the agreement between clinical and histopathological diagnosis among the skin punch biopsy we received in Gandaki Medical College Teaching Hospital (GMC-TH), Pokhara.

\section{MATERIALS AND METHODS}

This is a cross sectional retrospective study performed in the Department of Pathology, GMC-TH, Pokhara for the period of 6 months from $1^{\text {st }} J a n u a r y$ to $30^{\text {th }}$ June 2019. Skin punch biopsies were done from clinically diagnosed skin lesion of leprosy from the Department of Dermatology of GMC-TH and Greenpastuer's Hospital, Pokhara. The well labelled samples were received, processed and stained with Hematoxylin-Eosin (H\&E) and Fite Faraco (FF) stain wherever required. The prepared slides were evaluated by consultant pathologists. The H\&E stained sections were studied for the morphology of disease and to make diagnosis of different types of leprosy. The histopathological typing of leprosy was done according to Ridley and Jopling classification. ${ }^{3}$ In case of only nerve biopsy with features of leprosy, the different term, pure neuritic leprosy (PNL) was used. The FF stained sections were evaluated to see the Bacillary Index (BI) of the disease. The BI was calculated as given below: ${ }^{15}$

$\mathrm{BI}=0$ : no bacilli observed

$\mathrm{BI}=1: 1$ to 10 bacilli in 10 to 100 high-power fields (hpf, oil immersion)

$\mathrm{BI}=2: 1$ to 10 bacilli in 1 to $10 \mathrm{hpf}$

$\mathrm{BI}=3: 1$ to 10 bacilli per hpf

$\mathrm{BI}=4: 10$ to 100 bacilli per $\mathrm{hpf}$

$\mathrm{BI}=5: 100$ to 1000 bacilli per hpf

$\mathrm{BI}=6:>1000$ bacilli per hpf

The history and clinical examinations of patients regarding the nature of lesion was recorded with clinical differential diagnoses. The clinically diagnosed case of leprosy that differed on histopathology were categorised as different entity (others).

The data were collected filling the proforma and subjected to kappa analyses using Statistical Package for Social Sciences (SPSS version 24) to see the agreement between clinical and histopathological diagnosis. The kappa values and their interpretations were as follows: <0, no agreement; 0 to 0.19 , very weak agreement; 0.20 to 0.39 , weak agreement; 0.40 to 0.59 , moderate agreement; 0.60 to 0.79 , substantial agreement; and 0.8 to 1.0 , excellent agreement. ${ }^{14}$ The significance level used for the analyses was $5 \%(\mathrm{p}<0.05)$.

The ethical clearance for the study was obtained from GMC-Institutional Review Committee

\section{RESULTS}

Among the total of 62 cases, predominant of skin biopsies were received from male 39 (62.90\%) and remaining were from female patients.

Table 1: Frequency of cases with respects to age group and sex

\begin{tabular}{|c|c|c|c|}
\hline \multirow{2}{*}{$\begin{array}{l}\text { Age Range } \\
\text { (Years) }\end{array}$} & \multicolumn{2}{|c|}{ Sex } & \multirow{2}{*}{ Total } \\
\hline & Female & Male & \\
\hline $0-10$ & $1(1.6 \%)$ & $0(0 \%)$ & $1(1.6 \%)$ \\
\hline $11-20$ & $7(11.3 \%)$ & $2(3.2 \%)$ & $9(14.5 \%)$ \\
\hline $21-30$ & $8(12.9 \%)$ & $13(21.0 \%)$ & $21(33.9 \%)$ \\
\hline $31-40$ & $4(6.5 \%)$ & $6(9.7 \%)$ & 10 (16.1\%) \\
\hline $41-50$ & $1(1.6 \%)$ & $5(8.1 \%)$ & $6(9.7 \%)$ \\
\hline $51-60$ & $1(1.6 \%)$ & $2(3.2 \%)$ & $3(4.8 \%)$ \\
\hline $61-70$ & $1(1.6 \%)$ & $5(8.1 \%)$ & $6(9.7 \%)$ \\
\hline $71-80$ & $0(0 \%)$ & $3(4.8 \%)$ & $3(4.8 \%)$ \\
\hline $81-90$ & $0(0 \%)$ & $3(4.8 \%)$ & $3(4.8 \%)$ \\
\hline Total & $23(37.1 \%)$ & 39 (67.9\%) & $62(100 \%)$ \\
\hline
\end{tabular}

The age group is shown in table 1 . We received more skin biopsies from the patients aged 21 to 30 years i.e. 21 (33.9\%), followed by 31 to 40 years $10(16.1 \%)$ and least from the age group 0 to 10 years. The variable percentage of biopsies were received from other age groups. In all age groups there were male predominance except in 11 to 20 and 0 to 10 years.

Table 2: Clinical diagnosis of leprosy

\begin{tabular}{ccc}
\hline Clinical Diagnosis & Frequency & Percent \\
IL & 1 & 1.6 \\
BT & 6 & 9.7 \\
TT & 8 & 12.9 \\
BL & 13 & 21.0 \\
LL & 29 & 46.8 \\
PNL & 5 & 8.1 \\
Total & 62 & 100.0 \\
\hline
\end{tabular}

Note: IL: Indeterminate Leprosy, BT: Borderline Tuberculoid, TT: Tuberculoid Leprosy, BL: Borderline Lepromatous Leprosy, LL: Lepromatous Leprosy, PNL: Pure Neuritic Leprosy

The most common clinical diagnosis in our study was LL 
29 (46.8\%) followed by BL 13(21\%). The least common clinical diagnosis was IL One(1.6\%) as shown in Table 2.

Table 3 : Histopathological diagnosis of leprosy

\begin{tabular}{ccc}
\hline $\begin{array}{c}\text { Histopathological } \\
\text { Diagnosis }\end{array}$ & Frequency & Percent \\
IL & 10 & 16.1 \\
BT & 11 & 17.7 \\
TT & 1 & 1.6 \\
BL & 14 & 22.6 \\
LL & 19 & 30.6 \\
PNL & 4 & 6.5 \\
others & 3 & 4.8 \\
Total & 62 & 100.0 \\
\hline
\end{tabular}

In our study, LL was commonly diagnosed case19 (30.6\%) followed by BL 14 (22.6\%). TT was diagnosed only in one (1.6\%) case. (Table 3)

Table 4: Bacillary index with subtype of leprosy

\begin{tabular}{ccccccccc}
\hline \multirow{7}{*}{$\begin{array}{c}\text { Histopathological } \\
\text { Diagnosis }\end{array}$} & 0 & 1 & 2 & 3 & 4 & 5 & 6 & \\
\cline { 2 - 6 } IL & 8 & 2 & 0 & 0 & 0 & 0 & 0 & 10 \\
BT & 1 & 7 & 3 & 0 & 0 & 0 & 0 & 11 \\
TT & 1 & 0 & 0 & 0 & 0 & 0 & 0 & 1 \\
BL & 0 & 0 & 5 & 2 & 6 & 1 & 0 & 14 \\
LL & 0 & 0 & 0 & 0 & 4 & 8 & 7 & 19 \\
PNL & 0 & 1 & 2 & 0 & 1 & 0 & 0 & 4 \\
Others & 3 & 0 & 0 & 0 & 0 & 0 & 0 & 3 \\
Total & 13 & 10 & 10 & 2 & 11 & 9 & 7 & 62 \\
\hline
\end{tabular}

It was noted that IL, BT, TT had lower BI while LL and BL had higher BI. But the PNL had variable bacillary load. In the other granulomatous diseases besides leprosy, the BI was not applicable. (Table 4)

Table 5: Overall agreement and kappa values between

\begin{tabular}{|c|c|c|c|c|c|c|c|c|c|c|c|c|c|}
\hline \multirow{2}{*}{\multicolumn{2}{|c|}{ 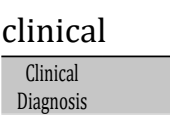 }} & \multicolumn{3}{|c|}{ and } & \multicolumn{6}{|c|}{ histopathological } & \multicolumn{3}{|c|}{ diagnosis } \\
\hline & & & & & & Hist & ppath & olog & ical Di & gnosis & & & P.value \\
\hline $\begin{array}{l}\text { Types of } \\
\text { Leprosy }\end{array}$ & $\begin{array}{l}\text { No. of } \\
\text { Patients }\end{array}$ & IL & BT & TT & BL & LL & PNL & BB & Others & Agreement & $\begin{array}{c}\text { Percentage } \\
(\%)\end{array}$ & $\begin{array}{c}\text { Kappa } \\
\text { Measurue of } \\
\text { Agreement }\end{array}$ & \\
\hline IL & 1 & 1 & - & - & - & - & - & - & - & $1 / 1$ & 100 & & \\
\hline BT & 6 & - & 6 & - & - & - & - & - & - & $6 / 6$ & 100 & & \\
\hline TT & 8 & - & 5 & 1 & - & - & - & - & 2 & $1 / 8$ & 12.5 & & \\
\hline BL & 13 & 4 & - & - & 8 & 1 & - & - & - & $8 / 13$ & 61.5 & & \\
\hline LL & 29 & 5 & - & - & 6 & 18 & - & - & - & $18 / 29$ & 62.1 & 0.505 & \\
\hline PNL & 5 & - & - & - & - & - & 4 & - & 1 & $4 / 5$ & 80 & & \\
\hline BB & 0 & - & - & - & - & - & - & - & - & - & - & & 0.001 \\
\hline Others & 0 & - & - & - & - & - & - & - & - & - & - & & \\
\hline Total & 62 & 10 & 11 & 1 & 14 & 19 & 4 & 0 & 3 & $38 / 62$ & 61.29 & & \\
\hline
\end{tabular}

As shown in table 5, there was $100 \%$ agreement between clinical and histopathological diagnosis of IL and BT. There was only $12.5 \%$ agreement on diagnosis of TT. Overall there was moderate agreement $(61.2 \%)$ between clinical and histopathological diagnosis (kappa- 0.505) which was statistically significant ( $\mathrm{p}$ value $<0.05$ ).

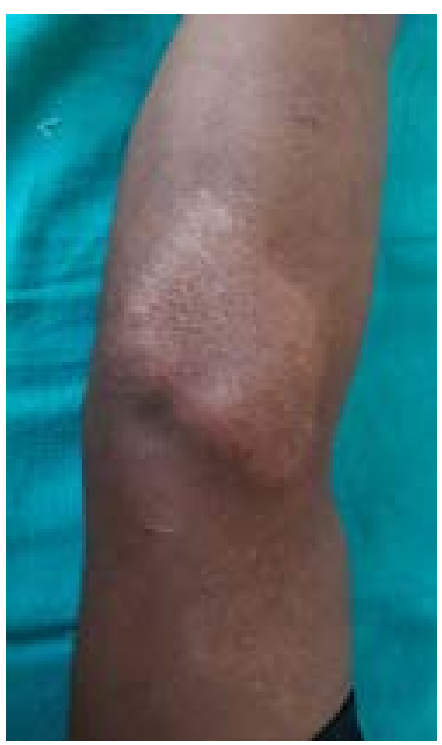

Fig.1: Hypopigmented patch in Hansen's disease. The lesion is located in extremity.

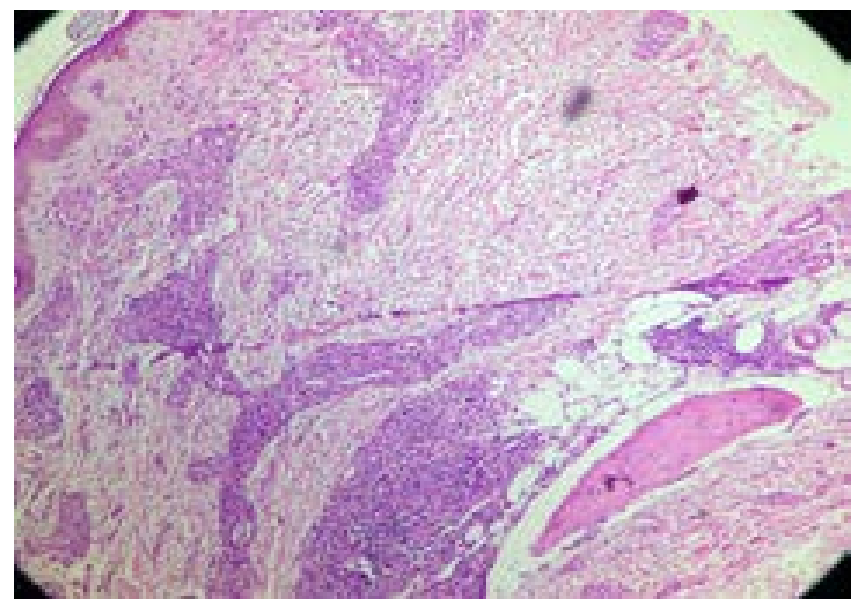

Fig. 2: Borderline Lepromatous Leprosy (BL) H\&E sections $(100 \mathrm{X})$. Section shows scattered epithelioid cells and foamy macrophages infiltrating dermal nerve and adenexal structures.

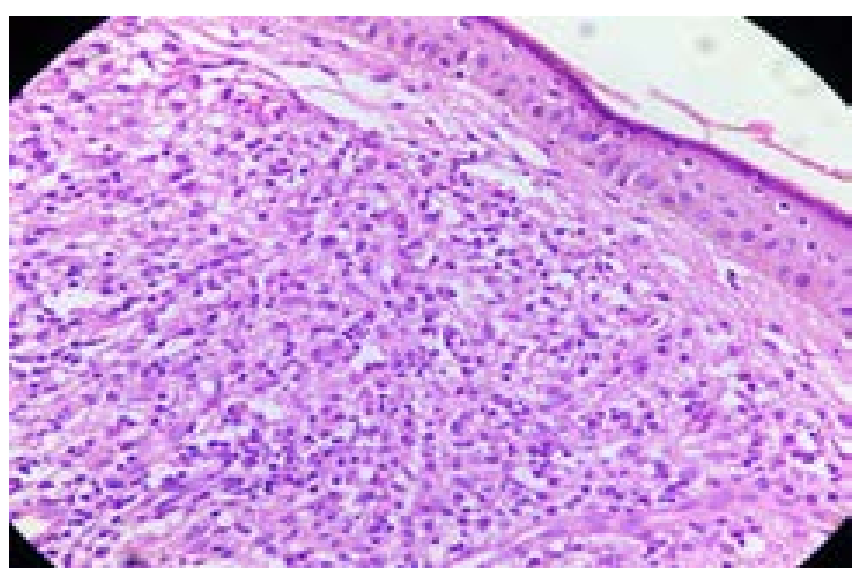

Fig.3: Lepromatous Leprosy (LL) H\&E Sections (400X). Section shows sheets of foamy macrophages in dermis with clear grenz zone in dermoepidermal junction. 


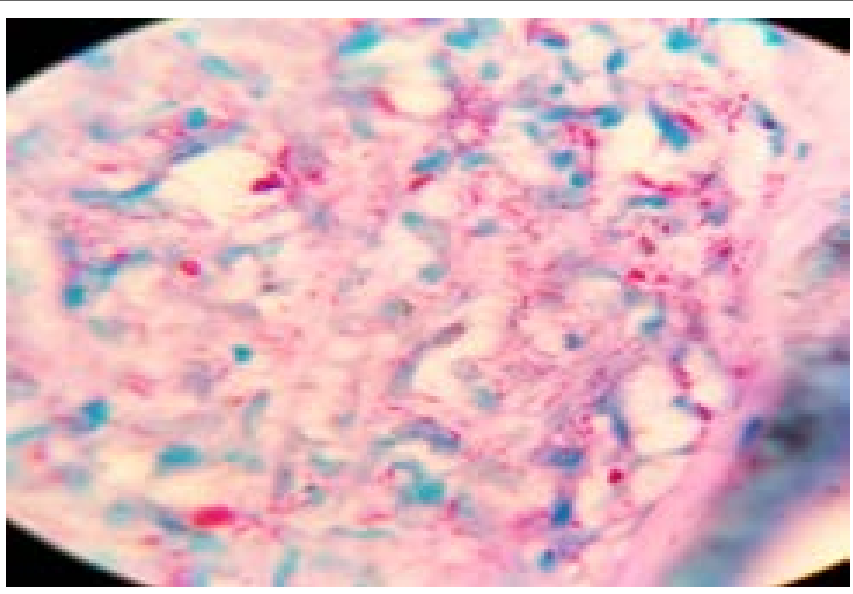

Fig.4: Bacillary Index- 6 (FF stain 1000X) Section shows globi of bacilli within leprae cells. This is the confirmatory findings of LL.

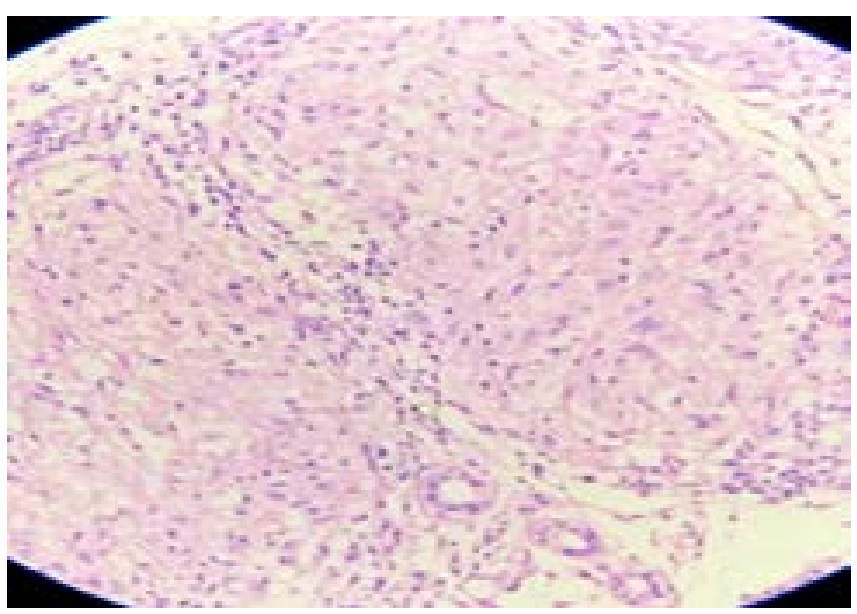

Fig. 5: Borderline Tuberculoid leprosy (H\&E 400X). Section shows epithelioid granuloma. Giant cells are not seen.

\section{DISCUSSION}

Leprosy is a chronic granulomatous disease which is common in countries like Nepal. It has two polar forms ranging from TT to LL based on the immune system of the host. The disease primarily affects the skin and nerve. ${ }^{7}$

The present study showed male preponderance for the disease $(62.90 \%)$. The higher male-to-female ratio (1.7:1) in our study could be due to increased number of males migrating to cities in search of employment. Similar findings were seen in the study conducted by Semwal et al., ${ }^{7}$ Karki et al. ${ }^{8}$ and Ramos et al. ${ }^{9}$ Male predominance is thought to be because of factors such as industrialization and urbanization which increases incidence for contact in males. ${ }^{10}$

In our study, the majority of patients belonged to the age group of 21 to 30 years (33.9\%) followed by 31 to 40 years (16.1\%) (Table1). This is similar to findings reported by Mathan R et al. ${ }^{16}$ with common age group of 21 to 40 years.
In contrast, the study done by De Vares et al. ${ }^{11}$ showed peak at 35 to 44 years. Though the percentage of children below 10 years in the study was only $1.6 \%$ and from 11 to 20 years was $14.5 \%$, it indicated that there has been a community transmission.

The histopathological diagnoses are categorized according to Ridley and Jopling Classification of leprosy. ${ }^{3}$ In our study, histopathologically, LL is found to be common lesion 19 (30.6\%) cases, followed by BL in 14 (22.6\%) cases whereas TT was less commonly diagnosed in $1(1.6 \%)$ case (Table 3$)$. In contrast, the study done by Bijarragi et al. ${ }^{17}$ showed BT (38\%) and IL (6.4\%). The morphology of two poles of spectrum of leprosy is different. In LL, dermis is infiltrated with sheets of foamy macrophages with clear grenz zone (Fig.3). The TT shows non caseating granuloma with Langhan's type giant cells encroaching the papillary dermis. Similarly, BT shows ill defined granuloma comprising of epithelioid histiocytes, but giant cells may be absent (Fig.5).

In the present study, three (4.8\%) clinically diagnosed cases of leprosy turned out to be other granulomatous disease histopathologically, similar findings were seen in study done by Lockwood et al. (7.1\%). ${ }^{13}$ This is because various granulomatous diseases can share the similar clinical features with similar type of skin lesions.

It is found that the $\mathrm{BI}$ is maximum in LL and BL where as IL, BT and TT had low BI (Table 4). The study conducted by Premalatha et al. ${ }^{10}$ and Semwal et al. ${ }^{7}$ also showed similar features of multibacillary in BL, LL and paucibacillary in TT and BT. The FF stained sections of BL and LL showed globi of bacilli within leprae cells with BI five to six (Fig.4) whereas IL, BT and TT had BI of upto three. This polarization of leprosy from TT to LL is due to impact of a differential immune response of $\mathrm{B}$ and $\mathrm{T}$ lymphocytes on the form of disease in the individual.

There was $100 \%$ agreement between clinical and histopathological diagnosis in IL and BT whereas it was least (12.5\%) in TT. Clinically diagnosed cases of TT are found to be BT. This disagreement might be because of similar clinical findings in the tuberculoid pole of the disease. In contrast to this, the study done by Moorthy B N et al. ${ }^{12}$ showed maximum clinico-pathological agreement in LL (80\%), followed by BL (70\%), TT (46.15\%) and least agreement was seen in IL (20\%).

The present study showed that overall there was moderate agreement (61.29\%) between clinical and histopathological diagnosis (kappa- 0.505) which was statistically significant ( $p$ value $<0.05$ ) (Table 5). Similar type of moderate agreement was seen in other studies 
done by Semwal et al..$^{7}(62 \%)$ and Moorthy B N et al. ${ }^{12}$ (62.63\%).

\section{CONCLUSION}

There is overall moderate agreement between the clinical and histopathological diagnosis of subtype of leprosy. The histopathological evaluation is essential to differentiate leprosy from other granulomatous diseases.

\section{Acknowledgements}

The authors express sincere thanks to Head and faculties of Department of Community Medicine, GMC-TH for their support in statistical analysis and guidance.

\section{Conflicts of Interest}

There are no conflicts of interest.

\section{REFERENCES}

1. Sujatha R, Nidhi P. Prevalence of leprosy in patients visiting a tertiary care center in Kanpur. Rama Univ J Med Sci. 2016:8-12.

2. Manandhar U, Adhikari RC, Sayami G. Clinicohistopathological correlation of skin biopsies in leprosy. J Pathol Nepal. 2013 Oct 24;3(6):452-8. DOI: 10.3126/jpn. v3i6.8992

3. Rodrigues Júnior IA, Gresta LT, Noviello Mde L, Cartelle CT, Lyon S, Arantes RM et al. Leprosy classification methods: a comparative study in a referral center in Brazil. Int J Infect Dis. 2016 Apr;45:118-22. DOI: 1016/j.ijid.2016.02.018

4. Walker SL and Lockwood DN. The clinical and immunological features of leprosy. Br Med Bull. 2006;7778:103-21. DOI: 10.1093/bmb/ldl010

5. Veldurthy VS, Shanmugam C, Sudhir N, Sirisha O, Motupalli CP, Rao N, et al. Pathological study of nonneoplastic skin lesions by punch biopsy. Int J Res Med Sci. 2017 Jan 10;3(8):1985-8. DOI: 10.18203/2320-6012. ijrms20150313

6. MamathaK, SusmithaS, PatilVS, VSK,B.sD. Histopathological spectrum of dermatological lesions - An experience at tertiary care centre. IP Arch Cytol Histopathol Res. 2018 Jul 15;3(2):83-8. DOI: 10.18231/2456-9267.2018.0017

7. Semwal S, Joshi D, Goel G, Asati D, Kapoor N. Clinicohistological correlation in Hansen's disease: Three-year experience at a newly established tertiary care center in central India. Indian J Dermatol. 2018 Nov 1;63(6):465.

8. Karki, S., \& Jha, R.. Limitations of Clinico-histopathological correlation of Skin Biopsies in Leprosy. Journal Of Nepal Health Research Council. Sept 2010. DOI: 10.33314/jnhrc. v0i0.222
9. Ramos JM, Martínez-Martín M, Reyes F, Lemma D, Belinchón I, Gutiérrez F. Gender differential on characteristics and outcome of leprosy patients admitted to a long-term care rural hospital in South-Eastern Ethiopia. Int J Equity Health. 2012 Oct 4;11:56. DOI: 0.1186/1475-9276-11-56

10. Premalatha P, Renuka I, Meghana A, Devi S, Charyulu P, Sampoorna G. Utility of Bacillary Index in Slit Skin Smears in Correlation with Clinical and Histopathological Alterations in Hansen's Disease: An Attempt to Revive a Simple Useful Procedure. Ann Med Health Sci Res. 2016;6(3):181-4. DOI: 10.4103/2141-9248.183936

11. De Vries JL, Perry BH. Leprosy case detection rates by age, sex, and polar type under leprosy control conditions. Am j epidemiol. 1985 Mar;121(3):403-13. DOI: 10.1093/ oxfordjournals.aje.a114012

12. Moorthy BN, Kumar P, Chatura KR, Chandrasekhar HR, Basavaraja PK. Histopathological correlation of skin biopsies in leprosy. Indian J Dermatol Venereol Leprol. 2001 Dec;67(6):299-301.

13. Lockwood DN, Nicholls P, Smith WC, Das L, Barkataki P, van Barkel W et al. Comparing the clinical and histological diagnosis of leprosy and leprosy reactions in the INFIR cohort of Indian patients with multibacillary leprosy. PLoS Negl Trop Dis. 2012;6(6):e1702. DOI: 10.1371/journal. pntd.0001702

14. Landis, J. Richard, Gary G. Koch. The Measurement of Observer Agreement for Categorical Data. Biometrics. 1997;33(1):159-74. DOI: 10.2307/2529310

15. Sebastian Lucas, Bacterial Diseases. In: David E. Elder, Bernnet Johnson, Jr, Rosalie Elenitsas and George F. Murphy. Lever's Histopathology of the Skin, 9th edition Lippincott Williams \& Wilkins, 2005, pp. 569-570.

16. Mathan R, Devan KM. Incidence and Clinical Profile of Leprosy in a Tertiary Care Hospital: A Retrospective Study. Int J Sci Stud. 2016;4(3):178-179

17. Bijjaragi S, Kulkarni V, Suresh KK, Chatura KR, Kumar P. Correlation of clinical and histopathological classification of leprosy in post elimination era. Indian journal of leprosy. 2012;84(4):271-5. 